\title{
Monitoring of Emission of Particulate Matter and Air Pollution using Lidar in Belgorod, Russia
}

\author{
Fedor Lisetskii", Andrei Borovlev \\ Federal-Regional Center of Aerospace and Surface Monitoring of the Objects and Natural Resources, Belgorod State \\ National Research University, Belgorod 308015, Russia
}

\begin{abstract}
Fine suspended particulate matter with an aerodynamic diameter smaller than $10\left(\mathrm{PM}_{10}\right)$ or $2.5 \mu \mathrm{m}\left(\mathrm{PM}_{2.5}\right)$ can be a dangerous air pollutant necessitating operational monitoring. Of the 1113 major Russian cities, however, only a few monitor industrial emissions of $\mathrm{PM}_{10}$ and $\mathrm{PM}_{2.5}$. Here, we develop an approach to using mobile multi-wave (1064, 532, and $355 \mathrm{~nm}$ ) lidar to estimate the concentration of $\mathrm{PM}_{10}$ and $\mathrm{PM}_{2.5}$. This approach was implemented for Belgorod, where 1378 sources of air pollution with anthropogenic dust, primarily of carbonate composition, were registered. We have developed algorithms with seven stages of assessing the spatial distribution and monitoring of $\mathrm{PM}_{10}$ and $\mathrm{PM}_{2.5}$, which made it possible to establish that fine-mode particles from tall sources of cement and construction material production (pipes with a height of $\geq 50 \mathrm{~m}$ ) contributed $39 \%$ of the total particulate matter emissions. Using GIS to map the fields of the total suspended particulate matter (TSP) and determining the ratios of $\mathrm{PM}_{10} / \mathrm{TSP}$ and $\mathrm{PM}_{2.5} / \mathrm{TSP}$, excesses in $\mathrm{PM}_{10}$ and $\mathrm{PM}_{2.5}$ up to 2.5 and 2.8 times greater, respectively, than the maximum threshold limit were observed. Tall sources' contribution to emissions increased in proportion to the distance from the source, resulting in $40-85 \%$ of the $\mathrm{PM}_{10}$ and $43-91 \%$ of the $\mathrm{PM}_{2.5}$. We demonstrate how lidar can be applied to optimize a particulate matter emissions monitoring network for environmental policy making.
\end{abstract}

Keywords: Particulate matters; Urban air pollution; Tall sources; Lidar measurements.

\section{INTRODUCTION}

A number of studies have shown that neither cloud cover nor precipitation can fully account for the observed temperature trends and that aerosols need to be considered (Portmann et al., 2009; Tosca et al., 2017). Fine suspended particulate matter (PM) with an aerodynamic diameter less than $10 \mu \mathrm{m}\left(\mathrm{PM}_{10}\right)$ and $2.5 \mu \mathrm{m}\left(\mathrm{PM}_{2.5}\right)$ are considered, with good reason, as significant pollutants, requiring systematic monitoring. In the USA and EU, threshold limit values (TLV) for $\mathrm{PM}_{10}$ and $\mathrm{PM}_{2.5}$ have been in existence for many years. Economic growth in Asian countries has stimulated the active development of control methods for PM for this region (Karimian et al., 2016; Lu et al., 2016; Munir et al., 2017). A special concern arises from enhanced mortality rates caused by the inhalation of $\mathrm{PM}_{10}$ and $\mathrm{PM}_{2.5}$ (Samoli et al., 2008). Atmospheric PM may adsorb a great number of pollutants from the air, which together may be ingested causing a toxic action, leading to development of cardiovascular,

\footnotetext{
* Corresponding author.

Tel.: +7-4722-30-13-70; Fax: +7-4722-30-10-12

E-mail address: liset@bsu.edu.ru
}

respiratory and cancerous diseases (Reche et al., 2012). $\mathrm{PM}_{2.5}$ poses a more serious threat to health than $\mathrm{PM}_{10} . \mathrm{PM}_{2.5}$ composition include water-soluble ions like $\mathrm{SO}_{4}{ }^{2-}, \mathrm{NO}_{3}{ }^{-}$, and $\mathrm{NH}_{4}^{+}$(Yang et al., 2017). In EU countries, 3\% of mortality from cardiovascular pathology and $5 \%$ of mortality from lung cancer are caused by $\mathrm{PM}_{2.5}$, and generally 3.1 million deaths per annum are caused by air pollution from $\mathrm{PM}_{2.5}$ (Cohen, 2004). Moreover, there is now no certain threshold below which $\mathrm{PM}_{2.5}$ would not pose some threat (European Union, 2008). A comparison of the current regulatory requirements for the content of $\mathrm{PM}_{10}$ and $\mathrm{PM}_{2.5}$ and also for the content of the total suspended PM (TSP) in the air is presented in Table 1 .

In 2010 in Russia hygienic standards (HS 2.1.6.2604-10) were introduced to establish TLV for $\mathrm{PM}_{10}$ and $\mathrm{PM}_{2.5}$. However, Russian systems monitor a maximum one-time concentrations of pollutants in the air (i.e., the particulate content over a 20 -minute averaging time). Presently, these methods for monitoring emissions into the air for $\mathrm{PM}_{10}$ and $\mathrm{PM}_{2.5}$ are insufficient. The subsequent accumulation of air pollutants caused by urban soils and other natural constituents is the basis for monitoring of urbanized ecosystems (Bulygin and Lisetskii, 1996). Therefore, new measurement approaches to assess compliance within these TLV for the protection of human health are necessary. 
Table 1. The Threshold Limit Values (TLV) and other criteria for the content of suspended particles in the air for the USA, Russia and on the recommendation of the WHO.

\begin{tabular}{|c|c|c|c|c|}
\hline \multirow{2}{*}{$\begin{array}{l}\text { Suspended } \\
\text { particles }\end{array}$} & \multirow{2}{*}{$\begin{array}{l}\text { Averaging } \\
\text { time }\end{array}$} & WHO & EU & Russia \\
\hline & & \multicolumn{3}{|c|}{$\mu \mathrm{g} \mathrm{m}^{-3}$} \\
\hline \multirow[t]{3}{*}{ TSP } & $20 \mathrm{~min}$ & - & - & 500 \\
\hline & 24 hours & - & - & 150 \\
\hline & 1 year & - & - & - \\
\hline \multirow[t]{3}{*}{$\mathrm{PM}_{10}$} & $20 \mathrm{~min}$ & - & - & 300 \\
\hline & 24 hours & 50 & $50^{\mathrm{a}}$ & 60 \\
\hline & 1 year & 20 & 20 & 40 \\
\hline \multirow[t]{3}{*}{$\mathrm{PM}_{2.5}$} & $20 \mathrm{~min}$ & - & - & 160 \\
\hline & 24 hours & 25 & 25 & 35 \\
\hline & 1 year & 10 & 12 & 25 \\
\hline
\end{tabular}

$\bar{a}$ the standard should not be exceeded more than 35 times during the year.

For many Russian industrial centers, including Belgorod, where monitoring of air pollution with $\mathrm{PM}_{10}$ and $\mathrm{PM}_{2.5}$ does not exist, monitoring of the spatial distribution of PM with a consideration to the degree of its dispersion in air and an assessment of total emissions is urgent (Sadovnikov et al., 2013). To solve the problem, we propose to integrate monitoring and the lidar method of probing, which gives a number of apparent advantages for operational non-contact collection of necessary data for aerosol concentration and emission sources in contrast to standard gravimetric methods.

Monitoring using dispersion models (calculated monitoring) implies regular efforts to determine the spatial and temporal characteristics of air pollution based on transfer and diffusion, while taking into account emissions sources and meteorological conditions. Mathematical models are used for monitoring primarily due to the fact that they are cheaper to deploy and use than instrument-based monitoring. For example, for a city the size of Belgorod, calculated monitoring will be 11.2 times cheaper (compared to servicing four monitoring stations) (Borovlev et al., 2013b).

Both single- and multi-wavelength lidars may be also used for these tasks. Probing at several wavelengths provides additional information of PM size and enables the discriminating of gas pollutions. In some instances, both single- and multi-wavelength lidars may be used (e.g., Behrendt et al., 2004; Weitkamp, 2005; Matvienko et al., 2014; Mammez et al., 2015). For example, such applications can be as atmospheric wind speed measurements (Lolli et al., 2013), aerosol detection and transport (Campbell et al., 2016), and gas concentration (Queißer et al., 2016; Dandocsi et al., 2017). The potential for adapting lidar measurements for the assessment of the spatial distribution of suspended PM is hypothesized here. This study aims to develop a methodological approach to using a mobile multi-wavelength lidar and mathematical simulation of PM distribution to control emissions, and the subsequent application of the results to an existing system of ecological control of the atmospheric boundary layer at monitoring stations in Belgorod. This allows us to obtain results of the pollutant distribution pattern over different functional zones of the industrial center, and a solution for improved efficiency in operational control over PM emissions $\left(\mathrm{PM}_{10}, \mathrm{PM}_{2.5}\right)$ into the air of a city where cement and construction are primary particulate sources.

Achieving this goal ensures a consistent solution to the following main tasks: (1) creation of a fully functional database of all sources of air pollution emissions in the city of Belgorod for calculating monitoring; (2) identification of priority sources, which provide the greatest contribution to urban air pollution by particles of $\mathrm{PM}_{10}$ and $\mathrm{PM}_{2.5}$, based on the GIS analysis of the mathematical simulation of the geographical distribution of suspended PM; (3) developing proposals for the organization of lidar control of source emissions of $\mathrm{PM}_{10}$ and $\mathrm{PM}_{2.5}$, with recommendations for mandatory use of the lidar measurements in case of detection exceedances of reference surface concentrations of TSP at monitoring stations.

\section{METHODOLOGY, METHODS AND STUDY AREA}

\section{Methodology}

Most monitoring stations administered by the Russian Federal Service for Hydrometeorology and Environmental Monitoring (Roshydromet) in the territory of Belgorod, as well as in many Russian cities, are located near highways, which in most cases result in overestimated pollution indexes. Because of this, the effectiveness of the Belgorod monitoring network cannot be considered satisfactory because of its relatively low informative value, both qualitatively and spatially. Therefore, to analyze urban industrial aerosols, including $\mathrm{PM}_{10}$ and $\mathrm{PM}_{2.5}$, it is advisable to use monitoring methods that allow for characterizing sources of industrial emissions, which make the greatest local contribution (for the functional zones of the city). We refer to this as priority sources for environmental control. Thus, if active monitoring is linked to a centralized monitoring system that allows for quickly mitigating priority sources of air pollution, the practical use of monitoring data is significantly expanded, which will improve the efficiency of the existing network.

This research is focused on the development of such a methodological approach, which could support an integrative system of lidar measurements and results of PM modeling within the existing monitoring network. The mathematical model, which is based on the solution of the atmospheric diffusion equation (Berlyand, 1991), is the one approved procedure for Russian monitoring operation (OND-86, 1987). Maximum one-time pollutant concentrations in OND-86 are calculated under relatively unfavorable meteorological conditions, meaning the absence of precipitation that could induce particle fallout, and thus the characteristics of vertical and horizontal turbulent mixing are combined unfavorably (Berlyand, 1991).

In accordance with this model, maximum one-time pollutant concentrations $\left(c_{\mathrm{m}}, \mathrm{mg} \mathrm{m}^{-3}\right)$ at the discharge of dust and air mixture from a single-point source is reached at a threshold wind speed $u_{\mathrm{M}}$ at a distance $x_{\mathrm{M}}$ from the source, determined by: 


$$
c_{M}=\frac{A \cdot M \cdot F \cdot m \cdot n \cdot \eta}{H^{2} \cdot \sqrt[3]{V_{1} \cdot \Delta T}}
$$

where $A$ is a coefficient that depends on the temperature stratification of the atmosphere, which determines the conditions for horizontal and vertical dispersion of pollutants in the air, $M$ is the mass of pollutants that is released into the air in a unit of time (injection capacity; $\left.\mathrm{g} \mathrm{s}^{-1}\right), F$ is a dimensionless coefficient that takes into account the sedimentation rate of pollutants (gaseous and aerosols, including particulate matter) in the air, $m$ and $n$ are dimensionless coefficients that take into account the conditions of emission at the source, $\eta$ is a dimensionless coefficient that takes into account the influence of the earth surface (geomorphology), $H$ is the height of the emission source $(\mathrm{m}), V_{1}$ is the dust and air mixture consumption $\left(\mathrm{m}^{3} \mathrm{~s}^{-1}\right)$, and $\Delta T$ is the difference between the temperature of the gas-air mixture and the air temperature $\left({ }^{\circ} \mathrm{C}\right)$.

Lidar profiling provides valuable information in addition to in situ measurements, since it allows for continuous long-term measurements with relatively high spatial and temporal resolution. Multi-wavelength lidar measurements contain information not only about the spatial distribution of the aerosol, but also about its microphysical parameters, such as the size distribution of aerosol particles and the refractive index of the aerosol substance (Weitkamp, 2005). The problem of determining the aerosol parameters using the backscatter coefficients at several wavelengths, represents a class of inverse problems that are solved using algorithms (Burton et al., 2014).

The optical parameters of the aerosol are found from the solution of the lidar equation (Measures, 1992), which connects the measured signals at the wavelength $\lambda_{k}(k=1$, $\ldots, N_{\lambda}$ ) with the optical parameters of the atmosphere, as:

$$
\begin{aligned}
& F\left(\lambda_{k}, z\right)= \\
& \left(\beta_{a}\left(\lambda_{k}, z\right)+\beta_{m}\left(\lambda_{k}, z\right)\right) \exp \left[-2 \int_{0}^{z}\left(\sigma_{a}\left(\lambda_{k}, z^{\prime}\right)+\sigma_{m}\left(\lambda_{k}, z^{\prime}\right)\right) d z^{\prime}\right]
\end{aligned}
$$

where $F\left(\lambda_{k}, z\right)=A\left(\lambda_{k}\right) P_{L}\left(\lambda_{k}, z\right) z^{2}, A\left(\lambda_{k}\right)$ is the hardware constant, $z$ is distance along the sounding path, $P_{L}\left(\lambda_{k}, z\right)$ is the lidar signal, $\beta_{a}\left(\lambda_{k}, z\right)$ and $\beta_{m}\left(\lambda_{k}, z\right)$ are the aerosol and molecular backscattering coefficients, and $\sigma_{a}\left(\lambda_{k}, z\right)$ and $\sigma_{m}\left(\lambda_{k}, z\right)$ are the attenuation coefficients from aerosol and molecular scattering.

The solution of Eq. (2) for a certain wavelength, $\lambda_{k}$, is obtained using transformations such as Fernald-Klett (Fernald, 1984; Klett, 1985), which can be written as follows (to reduce the notation for Eq. (3), we omit the variable $\lambda_{k}$ ):

$$
\beta_{a}(z)=-\sigma_{m}(z) \theta_{m}+\frac{\hat{F}(z, t)}{1+2 \int_{z}^{t} \frac{\hat{F}(z, t)}{\theta_{a}\left(z^{\prime}\right)} d z^{\prime}},
$$

$$
\begin{aligned}
& \hat{F}(z, t)= \\
& \frac{F(z) \beta\left(z_{g}\right)}{F\left(z_{g}\right)} T^{2}\left(t, z_{g}\right) \exp \left[-2 \int_{z}^{t} \sigma_{m}\left(z^{\prime}\right)\left(1-\theta_{a}\left(z^{\prime}\right)^{-1} \theta_{m}\right) d z^{\prime}\right],
\end{aligned}
$$

and

$$
\begin{aligned}
& T^{2}\left(t, z_{g}\right)=T_{m}^{2}\left(t, z_{g}\right) T_{a}^{2}\left(t, z_{g}\right), \\
& T_{a, m}^{2}\left(t, z_{g}\right)=\exp \left[-2 \int_{t}^{z_{g}} \sigma_{a, m}\left(z^{\prime}\right) d z^{\prime}\right] .
\end{aligned}
$$

Here $t$ is an arbitrary point on the sounding path, $\theta_{a}(z)=$ $\beta_{a}(z) / \sigma_{a}(z)$ and $\theta_{m}=\beta_{m}(z) / \sigma_{m}(z)$ are values that are called "lidar ratios" for aerosol and constant molecular backscatter to extinction coefficient (a synonym is the inverse ratios) (Hinkley, 1976; Measures, 1992). Point $z_{g}$ is the anchor point in which $\beta_{a}\left(\lambda_{k}, z\right)$ is assumed to be known. For $t \leq z$, the value of $T(t, z)$ is interpreted as the transparency of the atmosphere in the segment of the path $(t, z)$.

For assessment of spatial distribution of suspended PM (taking into consideration their degree of dispersion), and an arrangement of monitoring of emissions of $\mathrm{PM}_{10}$ and $\mathrm{PM}_{2.5}$, an algorithm was suggested, which includes seven stages of study:

1. Identification of priority sources, that is, those that have a determining contribution to total emissions of solid pollutants into the air, using source parameters in the created database.

2. Determination of size distribution of anthropogenic dust for these sources (using a focused-beam ion/electron microscope).

3. Measurements with the use of a combined semiautomated dust meter and a laser particle size analyzer of ground-level concentrations of TSP, $\mathrm{PM}_{10}$ and $\mathrm{PM}_{2.5}$ particles in the functional zones of the city for determination of the relations between $\mathrm{PM}_{10} / \mathrm{TSP}$ and $\mathrm{PM}_{2.5} / \mathrm{TSP}$ (conversion factors).

4. Numerical modeling of surface concentrations of TSP for the warm (April-November) and cold (JanuaryMarch, December) seasons.

5. GIS-mapping of TSP concentrations in the atmospheric boundary layer to obtain $\mathrm{PM}_{10}$ and $\mathrm{PM}_{2.5}$ concentration fields, taking into account the coefficients $\mathrm{PM}_{10} / \mathrm{TSP}$ and $\mathrm{PM}_{2.5} / \mathrm{TSP}$ for recalculating the TSP concentration for fine particles.

6. Analysis of the modeled results and GIS-mapping of surface concentrations of $\mathrm{PM}_{10}$ and $\mathrm{PM}_{2.5}$ along the residential area of the city, and the identification of priority sources for controlling emissions of $\mathrm{PM}_{10}$ and $\mathrm{PM}_{2.5}$, as well as the benchmark of surface concentrations of TSP at the pollution monitoring stations of the urbanized territory.

7. Lidar monitoring of emissions of $\mathrm{PM}_{10}$ and $\mathrm{PM}_{2.5}$ from local tall sources (pipes with a height of $\geq 50 \mathrm{~m}$ ) is conducted when benchmark pollution levels of surface TSP at the pollution monitoring stations are exceeded. 


\section{Methods}

Software for evaluating air pollution, widely used in Russia and other Commonwealth of Independent States members, was developed on the basis of OND-86. These, specifically, include the program "Ecologist" (Firm "Integral", St. Petersburg) that was used to derive estimates in our study. The regulatory dispersion model in OND-86 simulates the field of annual upper limits ( $98^{\text {th }}$ percentiles) of shortterm concentrations. On 1 January 2018 in Russia, a new regulatory document, "Method for calculation of diffusion of emissions of harmful substances (pollutants) into the air" (MCD), was introduced replacing OND-86. MNRE (2017) contain formulae for calculating the maximum onetime mean and annual mean PM concentrations, which allows them to be used to assess long-term effects of air pollution on the environment and to assess and minimize health risks. However, the model for the calculation of the maximum one-time ground-level concentrations, including the emissions of a single-point source of the fixed height, is the same as in OND-86.

The size distribution of dust in emissions from tall sources has been determined by experiment using a 3D focusedbeam ion/electron microscope (https:/www.fei.com/products/ sem/quanta-sem). Measurements of TSP mass concentration were carried out by gravimetric method with the use of a combined semi-automated dust meter, and a laser particle size analyzer was used for measurements of concentration of $\mathrm{PM}_{10}$ and $\mathrm{PM}_{2.5}$. Furthermore, the following methods have been applied in the study: cartographic analysis, mathand-stats methods, mathematical simulation and systemic functional analysis. The analysis of spatial distribution of ground-level concentrations of $\mathrm{PM}_{10}$ and $\mathrm{PM}_{2.5}$ regionally were carried out by methods of overlay, interpolation and spatial statistics and with the use of GIS-technologies.

\section{Study Area and Data Sources}

The subjects of the study were sources of air pollution located within the Belgorod agglomeration, having the center town Belgorod with an area of 15,600 ha and a population of 385,000 . The Belgorod agglomeration includes 600,000 people total, and is a capital of the region with intensive development of iron ore (i.e., Kursk Magnetic Anomaly) where environmental problems were previously recorded (Lisetskii et al., 2011), rational land use has been studied (Goleusov and Lisetsky, 2014) and impacts have been reported on water use (Lisetskii et al., 2014; Yermolaev et al., 2015). However, the high level of air pollution resulting from emissions of combustible products (caused by explosions in open pits) and metallurgy is also a problem.

In Belgorod alone, there exists mainly construction materials production factories, like for cement and chalkstone (Borovlev et al., 2013a). The annual emission of pollutants in Belgorod is $63,600 \mathrm{t}$ or $3.7 \mathrm{~kg}$ per person. The share of stationary sources in the volume of emissions is $11.5 \%$, and the share of motor vehicles is $88.5 \%$. About $98.0 \%$ of the volume of emissions from stationary sources comes from 56 large industrial enterprises (construction materials production factories, machine-building and metal-working factories, food industry factories and others). Gaseous and liquid fractions dominate emissions (97\%). As for solid pollutants, the main contribution to the contamination of the air basin is by emissions from stationary sources (98\%). Of these, $75.6 \%$ comes from cement ("Belgorod cement", Closed Joint-Stock Company [CJSC]).

We developed a database of pollution sources in Belgorod, which was used for the analysis of the distribution of volumes of emissions of PM. This database includes 2726 stationary sources, 1378 of which are sources of solid pollutants (including emissions from 11 large construction materials production factories), and 256 motorways with traffic intensity of more than 300 cars per hour (for peak traffic).

Three stationary observation sites (in system of Roshydromet) are located at distances of 50-60 m from highways and $3500-4000 \mathrm{~m}$ from the building materials and cement production, facilities which in most cases cause local overestimation of pollution by gaseous pollutants and underestimation by the amount of solid particles.

A mobile lidar system (MWL-60-MOB) mounted to a motor vehicle was applied. Lidar can operate in two modes of measurements: multi-wavelength modes (i.e., the measurements are made at wavelengths 355, 532 and $1064 \mathrm{~nm}$ ) and polarization mode (at $532 \mathrm{~nm}$ ). The main technical characteristics of the lidar, MWL-60-MOB, are given in Table 2. The source transmission unit of the lidar is a $1064 \mathrm{~nm}$ laser, which is doubled and tripled into separate channels. The $532 \mathrm{~nm}$ channel has a Glan-laser prism installed to calibrate the polarized receiving channels. The receiving telescope and transmitter are installed on an azimuth rotating unit, allowing for scanning at angles from 10 to $90^{\circ}$ and in azimuth from 0 to $360^{\circ}$. The goal of monitoring the rate of dust emissions is to determine the integral of the mass (volume) concentrations of aerosol, $\eta$, across an arbitrary cross-section of the plume and then multiply the result by the wind speed, $U$. The resulting value found in this manner is the pollutant flow, which for a stationary case will be equal to the rate or intensity of the emission $M$, as:

$M=U \int \eta(x, z) d z$

where $\eta$ is the linear integral of the concentrations of particles along the segment of the probing path $z$ that passes through the plume along the $\mathrm{x}$-axis and perpendicular to the middle direction of the wind.

The aerosol concentration is estimated based on the results of lidar measurements of its integral parameters. Multi-wavelength sensing, which makes it possible to determine the attenuation ratios for several wavelengths, was used to account for the variation in the micro-physical characteristics of the aerosol. This type of sensing was complemented by polarized profiling to identify the shape of the particles (Lidar, 2005; Matvienko et al., 2014; Chew et al., 2016). Eq. (3) in the case of multi-wavelength sensing is solved for all wavelengths jointly by an iterative method (Beard, 1974), and lidar relations are determined in the solution process. In order to determine the emission rate for finely dispersed particles, the volume concentrations of 
Table 2. Technical characteristics of the lidar MWL-60-MOB.

\begin{tabular}{ll}
\hline General characteristics & \\
\hline $\begin{array}{l}\text { Measured substances } \\
\text { Range of measurements, } \mathrm{km}\end{array}$ & $\begin{array}{l}\text { Aerosol, clouds } \\
\text { to } 10\end{array}$ \\
Vertical resolution, $\mathrm{m}$ & 15 (typically 150) \\
\hline Radiant & LS-2137 \\
\hline Laser & $1064,532,355$ \\
Wavelengths, nm & 550 \\
The energy of the pulse, MJ at the wavelength: & 300 \\
at wavelength $1064 \mathrm{~nm}$ & 120 \\
at wavelength $532 \mathrm{~nm}$ & $1-10$ \\
at wavelength $355 \mathrm{~nm}$ & not more than $15-28 \mathrm{~ns}$ \\
Pulse repetition frequency, Hz & not more than $1.5^{\prime}$ \\
The pulse duration of the laser radiation & \\
Angular divergence of the laser beam & 600 \\
\hline Receiver & $2-10^{\prime}$ \\
\hline $\begin{array}{l}\text { Diameter of the main telescope mirror, mm } \\
\text { Field of view of the telescope }\end{array}$ & 3 \\
Number of receiving channels & \\
Bandwidth of interference filters: & 4 nm \\
at wavelength $1064 \mathrm{~nm}$ & $2.5 \mathrm{~nm}$ \\
at wavelength $532 \mathrm{~nm}$ & $3.5 \mathrm{~nm}$ \\
at wavelength $355 \mathrm{~nm}$ & analogue \\
Signal processing mode & \\
\hline
\end{tabular}

the aerosol were estimated with an upper limit on the particle size, $\mathrm{V}_{2.5}$ and $\mathrm{V}_{10}$. The wind speed was determined based on measured data from a meteorological station, using the known links between wind speeds at the ground level and at an altitude (Nieuwstadt and Van Dop, 1982).

\section{RESULTS AND DISCUSSION}

The prevailing influence on pollution in the air above the city Belgorod was exerted by seven sources over $50 \mathrm{~m}$ high from the construction materials industry ("tall" sources according to OND-86). They included: six stacks from cement production factories, with heights of 65-96 $\mathrm{m}$, and one stack from a construction materials factory, with a height of $65 \mathrm{~m}$. The contribution to solid pollutant emissions from stationary sources was about $41.0 \%$. Of them, emissions from "tall" sources representing cement production factories reach $39.0 \%$ relative to all stationary sources. The size distributions of dust in the emissions from these tall sources, using the focused-beam ion/electron microscope showed that the share of $\mathrm{PM}_{2.5}$ in the air emissions from the cement production factories was $42.0 \%$, and the share of $\mathrm{PM}_{10}$ was $51.0 \%$. For emissions from the construction materials production factories, the share of $\mathrm{PM}_{2.5}$ was $45.0 \%$, and the share of $\mathrm{PM}_{10}$ was $50.0 \%$. Dust composition showed that the fraction of fine particles from construction materials tall sources was $39 \%$ relative to all PM.

Ground-level concentrations of TSP, $\mathrm{PM}_{10}$ and $\mathrm{PM}_{2.5}$ from twelve monitoring points in different functional zones around the city (residential, recreational, industrial, transport infrastructure) were available. During a calendar year (2015), 87 samples were taken for measurements of mass concentration of TSP by gravimetric method and by a semi-automated dust meter, and for measurements of $\mathrm{PM}_{10}$ and $\mathrm{PM}_{2.5}$ using a DustTrak Aerosol Monitor. The use of gravimetric method is necessary for calibration of the optical device, inspection of accuracy of its operation and determination of TSP. Of these, 15 samples characterized dust emissions when the dust collectors are turned off and the $\mathrm{CO}$ concentration reaches very high, dangerously explosive levels. The maximum emission of solid particles from tall sources located at altitude increases from 5 to $335 \mathrm{~g} \mathrm{~s}^{-1}$.

It has been suggested (Kim et al., 2006; Li et al., 2017; Munir, 2017; Xu et al., 2017) to use $\mathrm{PM}_{2.5} / \mathrm{PM}_{10}$ ratios as a relative indicator of fine particles. We analyzed 72 samples that characterized the standard emissions situation at the production facilities. The following ratios were obtained: $\mathrm{PM}_{10} / \mathrm{TSP}=0.59$ and $\mathrm{PM}_{2.5} / \mathrm{TSP}=0.39$. In this case, excess of $T_{L V}$ ms and annual mean concentrations of TLV (TLV $\left.\mathrm{am}_{\mathrm{m}}\right)$ for $\mathrm{PM}_{10}$ and $\mathrm{PM}_{2.5}$ were not detected. These ratios were characterized by certain stability and varied depending on TSP concentration, which gives grounds for simplification of the procedure for assessment of concentrations of $\mathrm{PM}_{10}$ and $\mathrm{PM}_{2.5}$ by means of their conversion from the determined TSP concentration. It should be noted that the ratios $\mathrm{PM}_{10} / \mathrm{TSP}$ and $\mathrm{PM}_{2.5} / \mathrm{TSP}$ were derived from measurements featuring cement emissions. For such cases, excesses of 1.2-1.8 times and 1.5-2.2 times were obtained for $\mathrm{TLV}_{\mathrm{ms}}$ $\mathrm{PM}_{10}$ and $\mathrm{TLV}_{\mathrm{ms}} \mathrm{PM}_{2.5}$, respectively. For this situation, the majority of particles of size $>10 \mu \mathrm{m}$ occurred on the underlying surface at a distance of up to $0.5 \mathrm{~km}$ from the emission sources, and the proportion of particles of size $<10 \mu \mathrm{m}$ increased with distance (Table 3 ). The typical duration of salvo cement emissions at the factories is 40$90 \mathrm{~min}$ at a frequency of 20-40 times a year, which 
Table 3. Distribution of suspended particles in the atmospheric air of Belgorod, 2015.

\begin{tabular}{llcc}
\hline Distance from high sources CJSC & \multicolumn{3}{c}{ The content of suspended particles of different fractions, \% } \\
\cline { 2 - 4 } "Belgorod cement", km & $>10 \mu \mathrm{m}$ & $2.5-10 \mu \mathrm{m}$ & $<2.5 \mu \mathrm{m}$ \\
\hline 0.5 & 53.2 & 26.6 & 20.2 \\
1.0 & 34.5 & 40.4 & 25.1 \\
2.0 & 22.6 & 45.1 & 32.3 \\
3.0 & 17.0 & 47.2 & 35.8 \\
4.0 & 8.7 & 49.8 & 41.5 \\
\hline
\end{tabular}

negates the differences in the fractional composition of the air in the situations we looked at. This means we can use the coefficients 0.59 and 0.39 we obtained in the simplified procedure for estimating concentrations of $\mathrm{PM}_{10}$ and $\mathrm{PM}_{2.5}$ from the concentration of TSP we determined.

The results of estimation-based monitoring showed that the maximum one-off concentrations of TSP in residential Belgorod occur at levels of $0.3-2.3 \mathrm{TLV}_{\mathrm{ms}}$, while the maximum annual average concentrations occur at $0.2-0.9$ $\mathrm{TLV}_{\mathrm{am}}$. The highest level of local pollution of TSP at 1.7-2.3 $\mathrm{TLV}_{\mathrm{ms}}$ for residential areas was recorded in the summer (Fig. 1). GIS-mapping of the ground-level TSP concentration fields, taking into account the ratio of $\mathrm{PM}_{10} / \mathrm{TSP}$ and $\mathrm{PM}_{2.5} / \mathrm{TSP}$, established maximum one-off concentrations of $\mathrm{PM}_{10}$ at $0.39-2.3 \mathrm{TLV}_{\mathrm{ms}}$ and $\mathrm{PM}_{2.5}$ at $0.4-2.8 \mathrm{TLV}_{\mathrm{ms}}$ and an average annual concentration of $\mathrm{PM}_{10}$ at $0.3-2.0$ $\mathrm{TLV}_{\mathrm{am}}$ and $\mathrm{PM}_{2.5}$ at $0.4-2.2 \mathrm{TLV}_{\mathrm{am}}$. By results of GISanalysis, a sector rigid 73.5 ha (2.2\% of the residential area) in the central district of the city was evaluated (Fig. 2). Excesses over $T L V_{m s}$ were caused, mainly, by tall sources of cement emissions (Fig. 2(f)). Their contribution to the values in excess of the $T L V_{m s}$ was over $50 \%$.

To solve the environmental problems caused by cement emissions, new standards were developed in 2017 that take into account targets for reducing dust emissions from tall sources $(15-30 \mathrm{~m})$. Modeling estimates that we carried out indicate that the measures put in place to reduce the emissions of cement production have succeeded at reducing concentrations of pollutants in the residential areas of the city to $0.8 \mathrm{TLV}_{\mathrm{ms}}$ and $0.7 \mathrm{TLV}_{\mathrm{am}}$ for $\mathrm{PM}_{10}$ and to $0.9 \mathrm{TLV}_{\mathrm{ms}}$ and $0.8 \mathrm{TLV}_{\mathrm{am}}$ for $\mathrm{PM}_{2.5}$. At the same time tall source emissions of fine PM should be closely watched. They make a sizable contribution to air pollution of fine PM, increasing in proportion to the distance from the source, resulting in $40-85 \%$ of the $\mathrm{PM}_{10}$ and $43-91 \%$ of the $\mathrm{PM}_{2.5}$. The relevance of monitoring of emissions of fine PM with tall sources is also borne out by the fact that the target emissions for these sources can be exceeded due to dust collector malfunctions.

These air pollution estimates can be significantly changed for the worse, given the trend towards harmonization of environmental standards in Russia with the EU. So, we will experience exceedances of average annual mean concentration for $\mathrm{PM}_{10}$ by 1.4 times and $\mathrm{PM}_{2.5}$ by 1.7 times if we use those $\mathrm{TLV}_{\mathrm{am}}$ that are accepted in the EU.

Information on compliance with PM emission standards is evaluated by comparison of TSP concentrations, which are measured maximum surface concentrations (reference concentrations) at stationary observation sites. Measured reference concentrations for the warm and cold seasons are shown in Table 4. If the TSP concentration exceeds the reference one, the violation of the established emission standards is counted. It is therefore necessary to carry out complementary monitoring using lidar of tall source emissions for solid pollutants into the air, which contribute greatly to the value of the reference measurements.

In Belgorod city, such monitoring was conducted for tall source emissions of industrial cement using lidar, which was located on high ground at a distance about $1.5 \mathrm{~km}$ from sources at the aforementioned production facility. The average temperature of the dust and gas mix that was coming out of the stacks into the atmosphere, as per the production process, was $100^{\circ} \mathrm{C}$. As a result of mixing with cold air, water vapor would condense resulting in the emergence of a visible plume. Profiling was performed in the turbulent diffusion zone of the mixture outside the observable plume. The distribution of the smoke stacks and residential structures in the area determined the minimal angle of the place (height) for the laser beam. Depending on the azimuth of the observations, this height was $30-50 \mathrm{~m}$. When the visible plume was sensed with a laser beam, a significant contribution was apparent in the back scattering by water vapor particles. For this reason, in order to estimate the integral parameters of the solid aerosol emissions, sensing was carried out under the lower edge of the visible plume in the turbulent mixture diffusion area.

Fig. 3(a) presents a schematic diagram of the lidar measurements. The lidar is located at the point $L$, and sensing directions $L A$ and $L B$ differ in azimuth at the fixed position angle. Thus, the route passes $L B$ in the area that is free of emissions from pipes and gives a background signal of the inverse dispersion $P_{B}(R)$ from a relatively "clean atmosphere," depending on the distance $R$ along the path. The sensing route passes $L A$ under the plume and yields a signal, $P_{S}(R)$.

Fig. 3(b) demonstrates the method for determining the under-plume aerosol optical thickness and its mean aerosol extinction coefficient, and shows the adjusted square distances of the logarithms of the signals $\mathrm{P}_{\mathrm{B}}$ and $\mathrm{P}_{\mathrm{S}}$ conditionally. The signals for the lines $A B$ and $C D$ are:

(AB) $\ln P_{s}(R)=\ln P_{B}(R)+K+\delta\left(\ln P_{B}(R)\right)$ and

(CD) $\ln P_{s}(R)=2 \tau_{S+} \ln P_{B}(R)+K+\delta\left(\ln P_{B}(R)\right)$

where $P_{B}(R)$ and $P_{S}(R)$ are signals of the inverse dispersion from "clean atmosphere" and under the plume respectively with range $R, \tau_{S}$ is the optical thickness of the aerosol "trace" under the plume, $K$ is independent from $R$ constant, and 


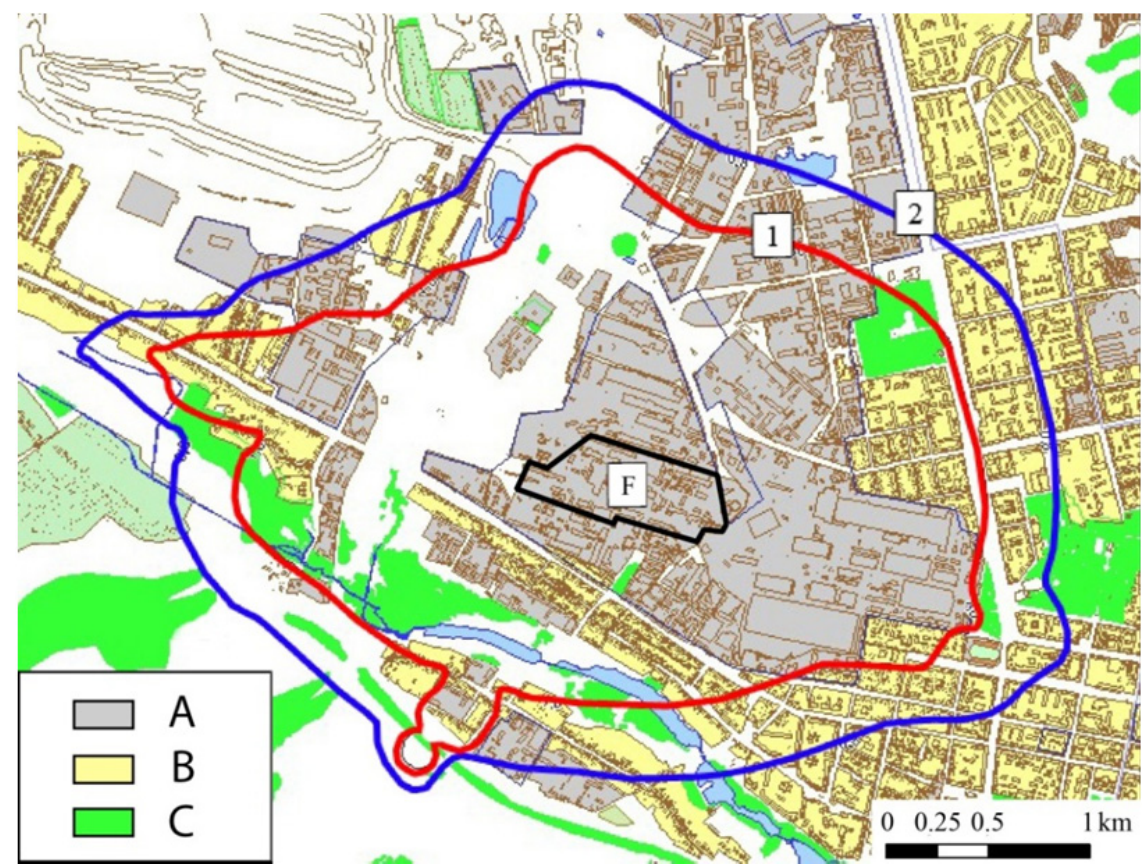

Fig. 1. Zones on the territory of the city of Belgorod, where there are excesses of the maximum single $\mathrm{TLV}_{\mathrm{ms}}$ of $\mathrm{PM}_{10}$ and $\mathrm{PM}_{2.5}$ : 1: $1.0 \mathrm{TLV}_{\mathrm{ms}}$ of $\mathrm{PM}_{10} ; 2$ : $1.0 \mathrm{TLV}_{\mathrm{ms}}$ of $\mathrm{PM}_{2.5}$. F: CJSC "Belgorod cement": A: industrial zone; B: residential zone; $\mathrm{C}$ : woodland; F: cement production factory (CJSC "Belgorod cement"); — isolines of air pollution of TSP (the share of $\left.\mathrm{TLV}_{\mathrm{ms}}\right)$.

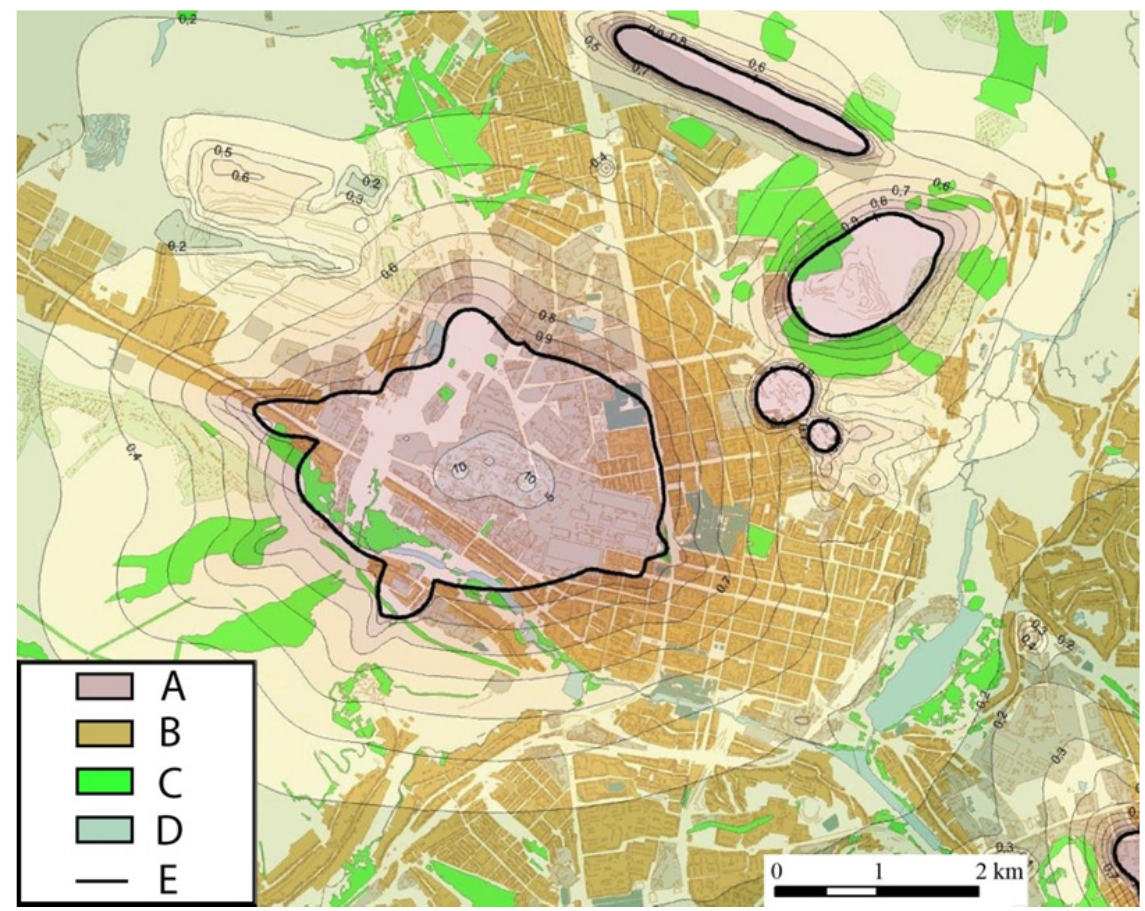

Fig. 2. Maximum surface concentrations of TSP in the city of Belgorod (the warm period of the year), the share of TLV $\mathrm{m}_{\mathrm{ms}}$ A: zone of elevation of $\mathrm{TLV}_{\mathrm{ms}}$; B: zone of non-elevation of $\mathrm{TLV}_{\mathrm{ms}}$; C: woodland; D: recreational area; — isolines of air pollution of TSP (the share of TLV $\mathrm{ms}_{\mathrm{ms}}$ ).

$\delta\left(\ln P_{B}(R)\right)$ is signal fluctuations caused by error of signals record and small-scale fluctuations of optical characteristics of background aerosol environment.

In the case of a small fluctuations, Eq. (5) provides the ratio for determination of $\tau_{S}$ as:
$\tau_{S}=0,5\left[\left\langle\ln P_{S}(R)-\ln P_{B}(R)\right\rangle_{A B}\right]-\left[\left\langle\ln P_{S}(R)-\ln P_{B}(R)\right\rangle_{C D}\right]$,

where the symbol \langle\rangle denotes averaging over segments $\mathrm{AB}$ or CD. 
Table 4. Reference surface concentrations of TSP, $\mathrm{PM}_{10}, \mathrm{PM}_{2.5}$ at the stationary observation sites at environmental control of $\mathrm{PM}_{10}$ and $\mathrm{PM}_{2.5}$ emissions from CJSC "Belgorod cement"

\begin{tabular}{|c|c|c|c|c|c|}
\hline \multirow{2}{*}{$\begin{array}{l}\text { Particulate } \\
\text { matter }\end{array}$} & \multirow{2}{*}{$\begin{array}{l}\text { Number of the stationary } \\
\text { observation posts }\end{array}$} & \multicolumn{2}{|c|}{ Reference surface concentration $\left(\mathrm{mg} \mathrm{m}^{-3}\right)$} & \multirow{2}{*}{$\begin{array}{l}\text { Direction of } \\
\text { the wind }\end{array}$} & \multirow{2}{*}{$\begin{array}{l}\text { Share of the tall } \\
\text { sources }(\%)\end{array}$} \\
\hline & & warm season & cold season & & \\
\hline \multirow[t]{3}{*}{ TSP } & 3 & 0.32 & 0.23 & NW & 37.1 \\
\hline & 6 & 0.36 & 0.22 & SW & 39.2 \\
\hline & 7 & 0.129 & 0.11 & NW & 75.9 \\
\hline \multirow[t]{3}{*}{$\mathrm{PM}_{10}$} & 3 & 0.182 & 0.132 & NW & 40.1 \\
\hline & 6 & 0.2 & 0.127 & SW & 42.9 \\
\hline & 7 & 0.072 & 0.06 & NW & 84.6 \\
\hline \multirow[t]{3}{*}{$\mathrm{PM}_{2.5}$} & 3 & 0.107 & 0.079 & NW & 43.1 \\
\hline & 6 & 0.12 & 0.075 & SW & 46.2 \\
\hline & 7 & 0.041 & 0.032 & NW & 91.1 \\
\hline
\end{tabular}
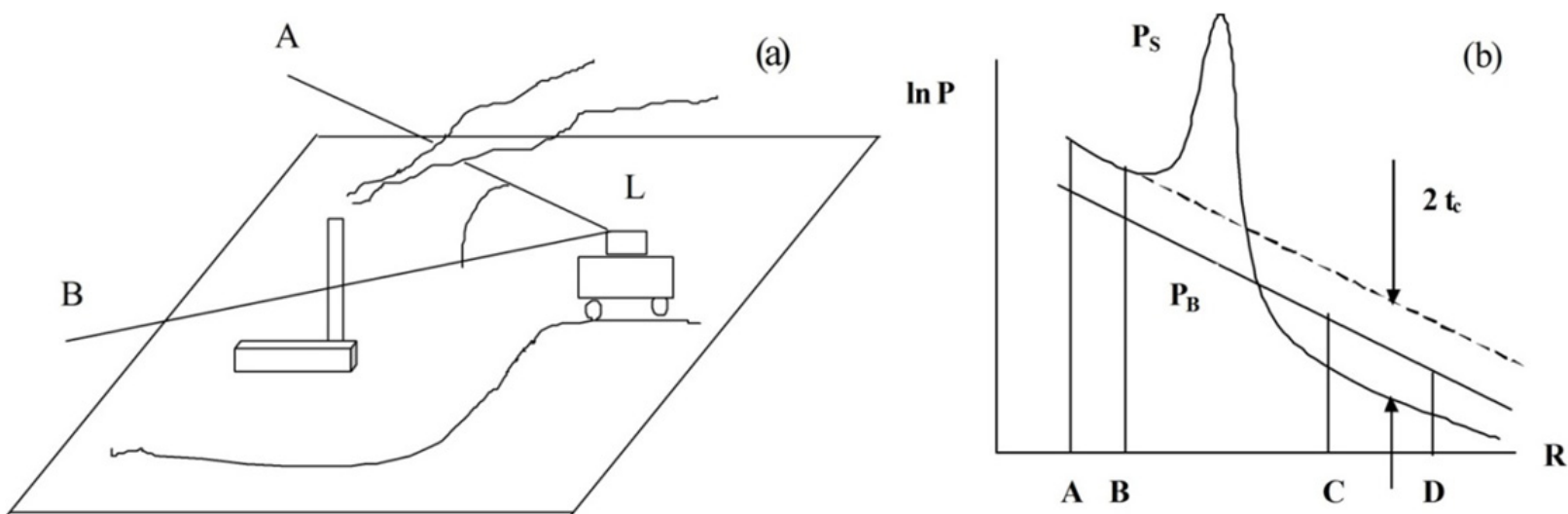

Fig. 3. The scheme for conducting lidar measurements to determine the optical thickness of the flare: (a) measurement scheme: sounding under the flare along the $L A$ line gives the signal $P_{S}$, probing the "clean atmosphere" along the line $L B$ gives the signal $P_{B}$; (b) the determination of the optical thickness (shown by arrows) from the comparison of signals $P_{S}$ and $P_{B}$.

The procedure for estimating the percentage of liquid and solid aerosols in the industrial emissions involves the use of the polarized lidar signal. Polarized sensing was done for three typical cases: clean air, a visually observable aerosol plume coming out of the smoke stack, and an aerosol trail under the plume. The results indicate that the observable part of the plume is a dense aerosol comprised primarily of spherical water vapor droplets. Outside the visible plume, there is aerosol comprised of non-spherical particles that are spreading as a result of turbulent diffusion. The signal depolarization from the aerosol was $39-40 \%$.

Measurements of the optical thicknesses on three wavelengths $(355,532$, and $1064 \mathrm{~nm})$ allowed us to construct a particle size distribution function and then estimate the integral parameters of the aerosol, including particle radius $r_{32}(\mu \mathrm{m})$, area of particles per unit volume of air $S\left(\mu \mathrm{m}^{2} \mathrm{~cm}^{-3}\right)$, volume of particles per unit volume of air $V\left(\mu \mathrm{m}^{3} \mathrm{~cm}^{-3}\right)$, and aerosol extinction coefficient at a wavelength of $532 \mathrm{~nm}\left(\mathrm{~km}^{-1}\right)$. The integral parameters were determined for dry and liberally moisturized states of the dust (refractive indices of $n=1.55-0.005 i$ and $n=$ 1.41-0.002i, respectively).

Analysis of the experimental data showed that the average mass concentration varied by no more than $15 \%$, which means that variations in the refractive index are not critical relative to the aerosol mass concentration estimates for $r_{32}$ in the area $0.6-1.2 \mu \mathrm{m}$. The difference obtained for the specific surface area of the particles $(S)$ was even less. Microscopic analysis of the dust samples showed that most of the particles had a size of 2-4 $\mu \mathrm{m}$ and elongated shapes (or radii not $>2 \mu \mathrm{m}$ when replaced with equivalent spheres), which agrees satisfactorily with the results of the lidar measurements.

On the whole, the results of the study we conducted suggest that with three wavelength sensing measurements we can estimate the integral parameters of aerosol, $S$, $\sigma$ (532), $V$ and $r_{32}$, on condition that the refractive index $n$ and its error \pm 0.05 are known in advance. In this case, the aforementioned parameters can be estimated with an error of no more than $25 \%$. Analysis of our data, obtained for five recent years of lidar observations, makes it possible to come up with the following general conclusions:

- $\mathrm{PM}_{2.5}$ are detected at a distance of over $3.5 \mathrm{~km}$ from tall emission sources. If the wind speed exceeds $2 \mathrm{~m} \mathrm{~s}^{-1}$, the width of the airborne plumes may increase from 50 to $700 \mathrm{~m}$;

- The main air pollutant in the residential zone of Belgorod is industrial cement production artifact, and the concentration of suspended PM at the height of $100-300 \mathrm{~m}$ reaches $0.003 \mu \mathrm{g} \mathrm{m}^{-3}$; 
- The size distribution of dominant PM from tall sources of the cement production factories is within the range of $2-4 \mu \mathrm{m}$.

The idea of controlling emissions of industrial by products from tall sources (detection of excess aerosol emissions) is based on taking lidar measurements when benchmark concentrations of TSP are exceeded at monitoring stations for specific wind directions (from tall emission sources to the monitoring stations).

For processing our lidar measurements of fine suspended $\mathrm{PM}$ in the plume of industrial emission, a special software package (Borovlev and Kungurtsev, 2008; Borovlev et al., 2013b) was used, which included:

- Using a series of horizontal contours and a utility for said application for determining the distribution of concentrations of suspended PM in the industrial plume (an example is shown mapping the distribution of $\mathrm{PM}_{10}$ concentrations on a map of Belgorod in Fig. 4);

- Determining the integral of the mass (volume) concentration of $\mathrm{PM}_{10}$ and $\mathrm{PM}_{2.5}$ through a crosssection of the plume and then multiplying it by the wind speed, as well as getting estimates for emissions rates of $\mathrm{PM}_{10}$ and $\mathrm{PM}_{2.5}$ and comparing them with the benchmark emission rate.

Thus, an integrative approach has been suggested for using mobile multi-wave $(1064,532$, and $355 \mathrm{~nm})$ lidar (MWL-60) and specialized software in estimating the emission rates of $\mathrm{PM}_{10}$ and $\mathrm{PM}_{2.5}$, and for adapting lidar measurements to the monitoring emission of TSP by gravimetric method common in Russia. As a result, standard and actual values of emissions of $\mathrm{PM}_{10}$ and $\mathrm{PM}_{2.5}$ from tall sources, obtained using laser based monitoring and mathematical simulation, may be compared. For the task of improving the promptness of monitoring PM emissions, a methodological approach is suggested, which is based on comparison of the results of lidar measurements and mathematical simulation of distribution of suspended PM concentrations.

\section{CONCLUSIONS}

In this paper uses an example of air pollution assessment for an industrial urban center of Russia (Belgorod) to demonstrate the importance of monitoring $\mathrm{PM}_{10}$ and $\mathrm{PM}_{2.5}$ emissions relative to established standards for air quality. When these emissions remain unmonitored (which is typical for many industrial centers in Russia), capturing the spatial distribution of suspended PM, taking into consideration its degree of aerial dispersion and the available monitoring within the city, including lidar technologies, becomes urgent. Hence, an algorithm for estimating the spatial distribution of the $\mathrm{PM}_{10}$ and $\mathrm{PM}_{2.5}$ based on numerical modeling was developed.

The results indicate that fine suspended particles from tall sources $(\geq 50 \mathrm{~m})$ contributed $39 \%$ of the total solid pollutants emitted from stationary sources in Belgorod. Factories producing cement and construction materials contributed $50-51 \%$ of the $\mathrm{PM}_{10}$ and $42-45 \%$ of the $\mathrm{PM}_{2.5}$. Although the mean annual concentrations for $\mathrm{PM}_{10}$ and $\mathrm{PM}_{2.5}$ in the residential zone did not exceed the $\mathrm{TLV}_{\mathrm{am}}$, the maximum TSP, caused by industrial and vehicular emissions, exceeded the $\mathrm{TLV}_{\mathrm{ms}}$ by $1.7-2.3$ times during the summer. The stable $\mathrm{PM}_{10} / \mathrm{TSP}(0.59)$ and $\mathrm{PM}_{2.5} / \mathrm{TSP}(0.39)$ ratios simplified the procedure for assessing the $\mathrm{PM}_{10}$ and $\mathrm{PM}_{2.5}$ levels via the TSP concentration, which was obtained by computational monitoring.

Lidar observations revealed that when emissions from high-production cement factories did not exceed the permitted levels, the dominant solid particles were 2-4 $\mu \mathrm{m}$ in diameter. Furthermore, a series of measurements

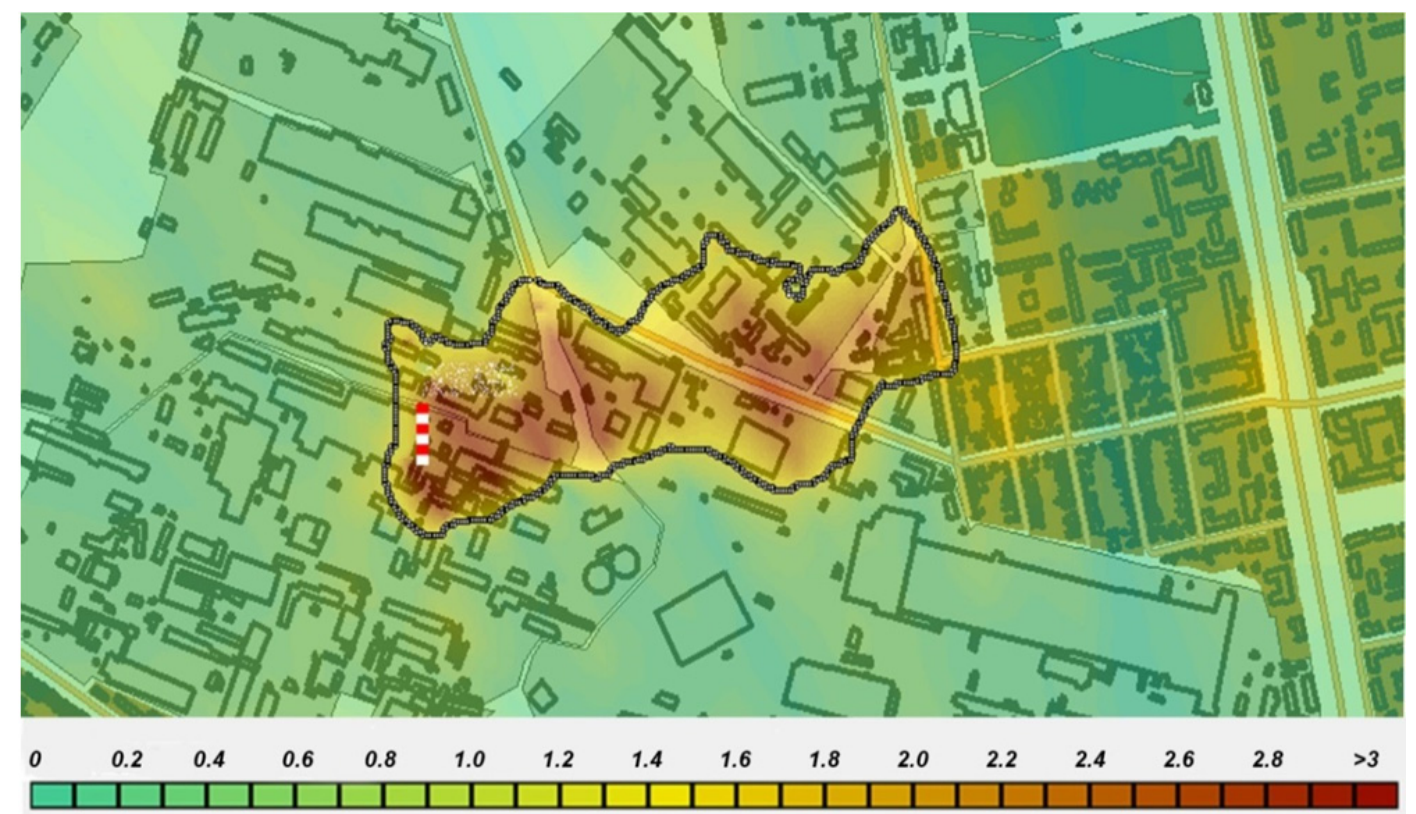

Fig. 4. Distribution of concentrations of $\mathrm{PM}_{10}\left(\mathrm{C} \cdot 10^{3}, \mu \mathrm{g} \mathrm{m}{ }^{-3}\right)$ at a height of $52 \mathrm{~m}$ using the results of lidar measurements. Sub-base: vector map of the territory of Belgorod. 
established that in cases of salvo emissions and exceedances, most particles that were $>10 \mu \mathrm{m}$ fell on the ground approximately $0.5 \mathrm{~km}$ from the factory, and the fraction composed by these particles increased with the distance from the source.

Excessive $\mathrm{PM}_{10}$ and $\mathrm{PM}_{2.5}$ was detected by comparing TSP concentrations observed at three stationary observation sites with the maximum measured values (reference concentrations). When the measured concentration exceeded the reference value, it was deemed necessary to conduct operational monitoring, first to measure emissions from the main sources of solid pollutants and then to assess the risk of pollutant deposition in the residential area of the city. Lidar is a promising technology for monitoring emissions from tall sources. In our study, we used mobile multi-wave lidar (MWL-60) and special software. The use of threewavelength $(1064,532$, and $355 \mathrm{~nm})$ and polarized $(532 \mathrm{~nm})$ lidar sensing enabled us to evaluate the size distribution of $\mathrm{PM}$ in industrial plumes and to discern complex particle shapes, which is a good addition to the numerical simulations of pollutant distribution patterns over different functional zones of the industrial center.

It has been suggested that the effectiveness of the existing monitoring system could be boosted by comparing the TSP concentrations measured at stationary monitoring stations with benchmark concentrations calculated for warm and cold periods. This study was conducted to integrate the data from lidar observation of $\mathrm{PM}_{10}$ and $\mathrm{PM}_{2.5}$ with TSP monitoring systems, thus increasing the effectiveness of the latter.

\section{ACKNOWLEDGMENTS}

This work was supported by the Ministry of Science and Education of the Russian Federation (the 2017-2019 state assignment for the Belgorod State National Research University, Project No. 5.4711.2017/6.7). The authors are very grateful to Dr. James Campbell and anonymous reviewers for their valuable comments and suggestions on our paper.

\section{REFERENCES}

Beard, K.V. (1974). Experimental and numerical collision efficiencies for submicron particles scavenged by small raindrops. J. Atmos. Sci. 31: 1595-1602.

Behrendt, A., Nakamura, T. and Tsuda, T. (2004). Combined temperature lidar for measurements in the troposphere, stratosphere, and mesosphere. Appl. Opt. 43: 2930-2939.

Berlyand, M.E. (1991). Prediction and regulation of air pollution. Vol. 14. Kluwer Academic Publishers, Dordrecht, The Netherlands.

Borovlev, A.E. and Kungurtsev, S.A. (2008). The hardware-software lidar complex as the element of geoinformation analytical system of city of Belgorod. Ecol. Syst. Devices 11: 56-59.

Borovlev, A.E., Kungurtsev, S.A., Solovyev, V.I. and Migal, L.V. (2013a). Solving practical tasks on norm setting for emission of suspended particles to the atmosphere over city Belgorod by using lidar measurement data. Ecol. Syst. Devices 6: 16-21.

Borovlev, A.E., Kungurtsev, S.A., Solovyev, V.I. and Migal, L.V. (2013b). The use of lidar measurements for the organization of monitoring compliance with standards of emissions of fine particulate matter in the ambient air of the city of Belgorod. Belgorod State Univ. Sci. Bull. Nat. Sci. 23: 145-149.

Bulygin, S.Y. and Lisetskii, F.N. (1996). Aggregate composition of soils, its assessment and monitoring. Eurasian Soil Sci. 29: 707-711.

Burton, S.P., Vaughan, M.A., Ferrare, R.A. and Hostetler, C.A. (2014). Separating mixtures of aerosol types in airborne High Spectral Resolution Lidar data. Atmos. Meas. Tech. 7: 419-436.

Campbell, J.R., Ge, C., Wang, J., Welton, E.J., Bucholtz, A., Hyer, E.J., Reid, E.A., Chew, B.N., Liew, S.C., Salinas, S.V., Lolli, S., Kaku, K.C., Lynch, P., Mahmud, M., Mohamad, M. and Holben, B.N. (2016). Applying advanced ground-based remote sensing in the Southeast Asian maritime continent to characterize regional proficiencies in smoke transport modeling. J. Appl. Meteor. Climatol. 55: 3-22.

Chew, B.N., Campbell, J.R., Hyer, E.J., Salinas, S.V., Reid, J.S., Welton, E.J., Holben, B.N. and Liew, S.C. (2016). Relationship between aerosol optical depth and particulate matter over Singapore: Effects of aerosol vertical distributions. Aerosol Air Qual. Res. 16: 28182830.

Cohen, A.J., Anderson, H.R., Ostro, B., Pandey, K.D., Krzyzanowski, M., Künzli, N., Gutschmidt, K., Pope III, C., Romieu, I. and Samet, J.M. (2004). Urban air pollution. In Comparative quantification of health risks: Global and regional burden of disease attributable to selected major risk factors. Ezzati, M., Lopez, A.D., Rodgers, A. and Murray, C.J.L. (Eds.), World Health Organization, Geneva, pp: 1353-1433.

Dandocsi, A., Nemuc, A., Marin, C. and Andrei, S. (2017). Measurements of aerosols and trace gases in southern Romania. Rev. Chim. 68: 873-878.

European Union (2008). Directive 2008/50/EC of the European Parliament and of the Council of 21 May 2008 on ambient air quality and cleaner air for Europe. Official Journal of the European Union. OJ L 152, 11.6.2008, p. 1-44.

Fernald, F.G. (1984). Analysis of atmospheric lidar observations: Some comments. Appl. Opt. 23: 652-653.

Goleusov, P.V. and Lisetsky, F.N. (2014). Restoration of soil and vegetation cover in post-mining geo-systems and their renaturation prospects in the area of the Kursk Magnetic Anomaly. Gornyi Zhurnal 8: 69-74.

Guo, W., Xia, N., Tiyip, T., Wang, J., Tashpolat, N. and Yang, C. (2017). Inversion of $\mathrm{PM}_{2.5}$ and $\mathrm{PM}_{10}$ content based on AOD data in large opencast coal mining area of Xinjiang. Trans. Chin. Soc. Agric. Eng. 33: 216-222. (in Chinese with English Abstract)

Hinkley, E.D. (1976). Laser monitoring of the atmosphere (Topics in Applied Physics. Vol. 14). Springer-Verlag, 
Berlin and New York.

Karimian, H., Li, Q., Li, C., Jin, L., Fan, J. and Li, Y. (2016). An improved method for monitoring fine particulate matter mass concentrations via satellite remote sensing. Aerosol Air Qual. Res. 16: 1081-1092.

Kim, Y.J., Kim, K.W., Kim, S.D., Lee, B.K. and Han, J.S. (2006). Fine particulate matter characteristics and its impact on visibility impairment at two urban sites in Korea: Seoul and Incheon. Atmos. Environ. 40: 593-605.

Klett, J.D. (1985). Lidar inversion with variable backscatter/extinction ratios. Appl. Opt. 24: 1638-1643.

Li, X., Ma, Y., Wang, Y., Liu, N. and Hong, Y. (2017). Temporal and spatial analyses of particulate matter $\left(\mathrm{PM}_{10}\right.$ and $\mathrm{PM}_{2.5}$ ) and its relationship with meteorological parameters over an urban city in northeast China. Atmos. Res. 198: 185-193.

Lisetskii, F.N., Borovlev, A.E., Chepelev, O.A., Terekhin, E.A. and Lomivorotova, O.M. (2011). Monitoring technogenic influence in acting and newly created industrial areas (for example, the Belgorod region). Ecol. Syst. Devices 7: 30-35.

Lisetskii, F.N., Pavlyuk, Y.V., Kirilenko, Z.A. and Pichura, V.I. (2014). Basin organization of nature management for solving hydroecological problems. Russ. Meteorol. Hydrol. 39: 550-557.

Lolli, S., Delaval, A., Loth, C., Garnier, A. and Flamant, P.H. (2013). 0.355-micrometer direct detection wind lidar under testing during a field campaign in consideration of ESA's ADM-Aeolus mission. Atmos. Meas. Tech. 6: 3349-3358.

Lu, H.Y., Mwangi, J.K., Wang, L.C., Wu, Y.L., Tseng, C.Y. and Chang, K.H. (2016). Atmospheric $\mathrm{PM}_{2.5}$ characteristics and long-term trends in Tainan city, Southern Taiwan. Aerosol Air Qual. Res. 16: 2488-2511.

Weitkamp, C. (Ed.) (2005). Lidar: Range-resolved optical remote sensing of the atmosphere series, Springer series in optical sciences, 102, Springer Science \& Business, New York, USA.

Mammez, D., Cadiou, E., Dherbecourt, J.B., Raybaut, M., Melkonian, J.M., Godard, A., Gorju, G., Pelon, J. and Lefebvre, M. (2015). Multispecies transmitter for DIAL sensing of atmospheric water vapour, methane and carbon dioxide in the $2 \mu \mathrm{m}$ region. Proc. SPIE 9645, Lidar Technologies, Techniques, and Measurements for Atmospheric Remote Sensing XI, 964507.

Matvienko, G.G., Belan, B.D., Panchenko, M.V., Romanovskii, O.A., Sakerin, S.M., Kabanov, D.M., Turchinovich, S.A., Turchinovich, Y.S., Eremina, T.A., Kozlov, V.S., Terpugova, S.A., Pol'kin, V.V., Yausheva, E.P., Chernov, D.G., Zuravleva, T.B., Bedareva, T.V., Odintsov, S.L., Burlakov, V.D., Arshinov, M.Y., Ivlev, G.A., Savkin, D.E., Fofonov, A.V., Gladkikh, V.A., Kamardin, A.P., Belan, D.B., Grishaev, M.V., Belov, V.V., Afonin, S.V., Balin, Y.S., Kokhanenko, G.P., Penner, I.E., Samoilova, S.V., Antokhin, P.N., Arshinova, V.G., Davydov, D.K., Kozlov, A.V., Pestunov, D.A., Rasskazchikova, T.M., Simonenkov, D.V., Sklyadneva, T.K., Tolmachev, G.N., Belan, S.B., Shmargunov, V.P., Rostov, A.P., Tikhomirova, O.V., Shefer, N.A., Safatov,
A.S., Kozlov, A.S., Malyshkin, S.B. and Maksimova, T.A. (2014). Complex experiment on the study of microphysical, chemical, and optical properties of aerosol particles and estimation of atmospheric aerosol contribution in the Earth radiation budget. Proc. SPIE 9292, 20th International Symposium on Atmospheric and Ocean Optics: Atmospheric Physics, 929254.

Measures, R. (1992). Laser remote sensing of the atmosphere. John Wiley \& Sons, New York, USA.

MNRE (Ministry of Natural Resources and Environment of the Russian Federation) (2017). On the approval of methods for calculating the dispersion of harmful (polluting) substances in the atmosphere. Order of June 6, 2017, n 273. https://www.garant.ru/products/ipo/pr ime/doc/71642906.

Munir, S. (2017). Analysing temporal trends in the ratios of $\mathrm{PM}_{2.5} / \mathrm{PM}_{10}$ in the UK. Aerosol Air Qual. Res. 17: 34-48.

Munir, S., Habeebullah, T.M., Mohammed, A.M.F., Morsy, E.A., Rehan, M. and Ali, K. (2017). Analysing PM $_{2.5}$ and its association with $\mathrm{PM}_{10}$ and meteorology in the arid climate of Makkah, Saudi Arabia. Aerosol Air Qual. Res. 17: 453-464.

Nieuwstadt, F.T.M. and Van Dop, H. (Eds). (1982). Atmospheric turbulence and air pollution modelling. D. Reidel Publishing, Dordrecht, the Netherlands.

OND-86 (1987). Method for calculating atmospheric concentration of hazardous substances contained in industrial emissions. Goskomgidromet 192. http://docs. cntd.ru/document/1200000112.

Portmann, R.W., Solomon, S. and Hegerl, G.C. (2009). Spatial and seasonal patterns in climate change, temperatures, and precipitation across the United States. Proc. Natl. Acad. Sci. U.S.A. 106: 7324-7329.

Queißer, M., Granieri, D. and Burton, M. (2016). 2-D tomography of volcanic $\mathrm{CO}_{2}$ from scanning hard-target differential absorption lidar: The case of Solfatara, Campi Flegrei (Italy). Atmos. Meas. Tech. 9: 5721-5734.

Reche, C., Moreno, T., Amasto, F., Viana, M., van Drooge, B., Chang, H., Berube, K., Jones, T., Alastuey, A. and Querl, X. (2012). A multidisciplinary approach to characterize exposure risk and toxicological effects of $\mathrm{PM}_{10}$ and $\mathrm{PM}_{2.5}$ samples in urbane environments. Ecotoxicol. Environ. Saf. 78: 327-335.

Sadovnikov, R.N., Boyko, A.Y. and Shlygin, P.E. (2013). Usage of lidar sensing for the estimation of control accuracy of chemical environment in the area of toxic substance cloud spreading in the course of accident at the chemical plant. Ecol. Syst. Devices 1: 35-41.

Samoli, E., Peng, R., Ramsay, T., Pipikou, M., Touloumi, G., Dominici, F., Burnett, R., Cohen, A., Krewski, D., Samet, J. and Katsouyanni, K. (2008). Acute effects of ambient particulate matter on mortality in Europe and North America: Results from the APHENA study. Environ. Health Perspect. 116: 1480-1486.

Tosca, M.G., Campbell, J., Garay, M., Lolli, S., Seidel, F.C., Marquis, J. and Kalashnikova, O. (2017). Attributing accelerated summertime warming in the Southeast United States to recent reductions in aerosol burden: Indications 
from vertically-resolved observations. Remote Sens. 9: 674.

Yang, X., Cheng, S., Li, J., Lang, J. and Wang, G. (2017). Characterization of chemical composition in $\mathrm{PM}_{2.5}$ in Beijing before, during, and after a large-scale international event. Aerosol Air Qual. Res. 17: 896-907. Yermolaev, O.P., Lisetskii, F.N., Marinina, O.A. and Buryak, Z.A. (2015). Basin and eco-regional approach to optimize the use of water and land resources. Biosci. Biotechnol. Res. Asia 12: 145-158.

Received for review, December 25, 2017 Revised, November 16, 2018 Accepted, January 29, 2019 